\title{
Party Girls and Predators: A Chronotope of Female Risk
}

\author{
Dawn Moore and Mariana Valverde
}

\begin{abstract}
Party Girls and Predators situe dans un contexte historique les récentes campagnes de sensibilisation aux «drogues de viol », campagnes destinées aux jeunes étudiantes qui sont encouragées " en tant que sujets néo-libérales, à se sauver au moyen d'une constante surveillance et réduction du risque ». En présentant d'abord une discussion sur l'inflation des médias qui associent l'Ecstasy avec les autres « drogues de clubs » et « drogues de viol », Valverde et Moore considèrent ensuite la trajectoire historique et narrative des récits sur la traite des Banches du tournant du $20^{e}$ siècle qui évoquaient d'innocentes jeunes filles s'installant à la ville qui étaient.
\end{abstract}

\section{Places that Go Bump in the Night: The Genesis of a Panic?}

The fears and frissons experienced around the world on New Year's Eve 1999 were, in Toronto, exacerbated by the spectre of "date rape drugs." The popular tabloid The Toronto Sun featured a front-page headline in bold type that announced: "Women Warned Of Drugged Booze," and a subtitle that read, "Coroner, cops tell revelers to beware of date-rape drinks spiked with Ecstasy." Inside the paper, there were two anxiety-producing stories: "Y2K rape drug alert: Women told to watch drinks at New Year bashes," and "Ecstasy kills 8 this year: deadly designer drug popular with rave goers"' (30 Dec 1999: 1, 5).

Little corroboration for these fears about Ecstasy is available either in popular culture or in expert drug discourse. Ecstasy (MDMA) is an "upper" and does not put potential rape victims to sleep. It is generally associated with feelings of empathy and love, not sexual aggression. ${ }^{1}$ Nevertheless, The Sun's claims (and those of Ontario coroner Dr Jim Cairns, the social crusader-cum-pathologist who was the main source of the news) gain a certain legitimacy through their similarity and proximity to stories about other drugs (Rohypnol and GHB, mostly) that can produce stupor or intoxication and that have been, especially in the US, constructed by diverse authorities as posing a grave risk of rape. Many of 
these stories have been circulating, since $1996,{ }^{2}$ in a wide range of educational material on drugs, alcohol, and "party safety" aimed at youth, and can be found in educational pamphlets made and distributed by universities, Web-based information circulated by American drug "education" agencies and by sexual assault centres, and posters and workshops ${ }^{3}$ developed by campus safety and alcohol-and-drug education officers.

These materials will be examined momentarily, though it is unlikely that their combined influence was any greater than that of the infamous nighttime soap opera aimed at teenagers and undergraduates, Beverly Hills 90210, which devoted an episode to the celebration of Valentine's Day, 1998. In this particular episode, entitled "Cupid's Arrow," Valerie, a notentirely likeable party girl who is known for taking sexual risks, is shown at a night club with two male friends. One of the characters, Noah, plays the role of the trustworthy friend and benevolent protector. The other, Noah's brother, plays the villain. When Valerie's attention is distracted, Noah's brother slips some white powder into her drink. Much to his chagrin, however, Valerie ends up leaving the club with Noah, who proceeds to have sex with her while she is under the effects of the drug. The next morning, Valerie, clearly educated about date rape drugs, quickly removes herself to the hospital, where tests reveal the presence of Rohypnol in her blood.

The story's trite plot, virtually identical to turn-of-the-century "white slavery" narratives about innocent maidens moving to the city and being inveigled into a life of prostitution through "knock-out drops," is here given timeliness as well as plausibility through the contemporary spacetime of the club. In the materials produced by educational and law enforcement authorities, the club merges with raves, frat parties, and other leisure space-times inhabited by youth late at night, space-times thought to be fraught with sexual and pharmacological risks. Borrowing Mikhail Bakhtin's term "chronotope" - the spatially specific temporality that defines and is constituted by each major literary genre - we could argue that, although going to an expensive club downtown is very different from seeking out an unlicenced and unadvertised rave in a warehouse, from the point of view of the governing authorities, what we have is a single chronotope: the club/rave/large youth party. As we shall see, the literature on drug risks and party safety given to North American youth assumes that there is a specific spatio-temporal logic that unifies otherwise heterogeneous substances and activities. Certain sets of events that do not 
seem possible most of the time, are regarded as likely risks in that particular chronotope. In these settings, women are thought to be at great risk of being drugged and raped even by their good friends. This logic is chronotope-specific, in the sense that the use of drugs for the purpose of rape is something that never happens in the daytime in places such as coffee shops or doctor's offices.

The maidens-in-distress of the campus scene cannot rely on anyone to save them: like good neoliberal subjects, they can only save themselves through constant risk-monitoring and risk reduction. However, since the drugs supposedly impair the ability to make oneself and one's risks calculable, the essential tool of harm-reduction programmes and other neoliberal measures for managing drug risks, ${ }^{5}$ much is made of the need to mobilize others as protectors. These "others" are not white knights; rather, they are (female) friends. While deploying existing feminine friendship networks eulogized by feminism, however, these materials disavow the spectre of feminism. It was, of course, feminism that first mobilized groups of women against the risks of male violence and made masculine sexual threats calculable, as Stanko suggests, but the students and other young people to which these materials are addressed are never told this, and indeed are never provided with any explicitly feminist images, tropes, or risk analysis.

Club drugs, drugged clubbers: hybrid risk knowledges and the clubdrug chronotope

Rohypnol and GHB, the primary date rape drugs, are now headliners in the new classification - disseminated around the world by the large, powerful, and multiply linked web sites of the Drug Enforcement Administration (DEA) and the National Institute for Drug Abuse (NIDA) - of club drugs. NIDA recently designed a separate web page entitled "Clubdrugs.org," whose URL, as often happens with drug-education material aimed at American youth, does not reveal its official provenance. This website, though new, already has links to many non-government sites that try to fix the meaning of several substances (including Ecstasy, GHB, and Rohypnol) by promoting a "reefer madness" panic through such techniques as a lurid-colour picture of a "plain brain" compared to an apparently rotting "brain after Ecstasy" (see image at www.clubdrugs.org). The governance effects of "club drugs" could be regarded as illustrating some features of what we might call, after Jonathan Simon's 
"governing through crime," governing through chronotope. This works as follows: first, a space/time unit taken to exist prior to one's governing project (the club, the campus party) is used to unify and give an identity to otherwise heterogeneous and/or ill-defined risks, including pharmacological risks. The elusive rave, for example, is often defined, in journalistic as well as in official discourse, by reference to a supposed group preference for Ecstasy. But the social and even the chemical meaning of Ecstasy is in turn often defined by the space of its consumption, not by its pharmacology. For example, a lengthy, multi-illustrated feature article in Canada's largest circulation daily, The Toronto Star, entitled "Agonizing Ecstasy," purported to be about the pleasures and dangers of Ecstasy itself, but was in fact a journalistic account of raves and rave culture, as if the drug had no history or no current use outside of youthful raves (20 Nov. 1999: $\mathrm{A} 1+$ ).

In a move that may be characteristic of chronotopes of consumption, the space/time is assumed to define the substances consumed in it, but simultaneously, specific substances define the chronotope. The problem chronotope of the rave/club/campus party, while obviously full of pleasures, is thought to be simultaneously occupied by the risks of Rohypnol and GHB. Ecstasy - which used to be consumed primarily in psychotherapy sessions - has, as Eisner suggests, become wholly embedded, culturally if not in actual fact, in the club. Thus, via its metonymic relation to club culture, it has become a date rape drug despite its unsuitable pharmacokinetic properties. NIDA's classification puts Ecstasy in the same place as Rohypnol in the same social space (the club), and in the same quasi-medical space (the list of club drugs). The fact that, in many clubs, beer and joints are also consumed in rather large quantities by clubbers is not acknowledged: the space/time and the substances consumed are presented as existing in a locked, exclusive relationship.

Studies by cultural geographers have investigated how youth are constituted and governed through the stigmatization of certain spaces, but the club of "clubdrug.org" is best understood not as a space but as a chronotope, since these deviant spaces would not be considered drug-ridden or risky if visited at lunch. It is the combination of the space (club rather than restaurant) and time (after licencing hours) that creates the risky chronotope of the club/rave, which is then used to define and give content to the otherwise terminally vague phrase "club drugs." 
The risk produced through the club chronotope, contrary to what contemporary risk theorists would have us believe, is not solely produced and managed through rationally organized technologies deploying statistical calculations and clinical judgements. Insurance companies, epidemiologists, and forensic psychologists are all engaged in constituting risk, but they do not monopolize the field. Mary Douglas has usefully highlighted the persistence - even in the age of actuarialism - of everyday risks known to the archetypal "man in the street," the sort of risk that can just as easily be designated by the old-fashioned term "danger." But it is not always necessary or appropriate to divide knowledges using the binary opposition of expert vs. lay, scientific vs. common sense, that underlies the debate between Douglas and the proponents of the scientific rationalization thesis. The kind of risk constituted through pamphlets on party safety and through the TV show mentioned above cannot be classified as leading a life separate from that of medical science. Instead, virtually all the educational pamphlets and web sites examined for this article featured both melodramatic tales and information derived from scientific sources, and/or included scientific-looking formats such as bar graphs. The chronotope of "date rape drugs," then, is characterized by a highly mixed knowledge format. ${ }^{6}$ Medical information, Victorian melodrama, girls-justwanna-have-fun female group hedonism, War-on-Drugs and "scared straight" discourses, posed photographs with professional models, graphs providing quantitative information, and community-police-type lists of "safety tips" are all combined to form a powerful risk information hybrid which appeals simultaneously to virtually every dimension of a female student's experience and desire.

The chronotope of date rape drugs/club drugs cannot be reduced either to a poor version of scientific risk management or to an irrational outburst of fears that are not empirically justified. The date-rape-drug assemblage of complex risks and paranoid safety tips has a logic which owes more to the War on Drugs than to women's experience of violence, but using a "moral panic" framework tends to minimize both gender specific dangers and the often idiosyncratic physiological risks that club drugs share with many legal and illegal substances. The date rape drug chronotope is admittedly largely constituted by urban legends about unnamed women being raped somewhere else by unnamed men, ${ }^{7}$ but it is not a "folk" space. Rather, it is a hybrid space of governance, in which occasionally exaggerated medical and social information about risks circulates along- 
side many other kinds of texts, from feminist advice on sexual assault, to lurid tales of sexual risk. The force of the chronotope is such that a particular substance has its properties defined more by the space/time in which it is consumed (the after hours rave club) than by its pharmacology: club drug becomes a category of governance even though its content cannot be either legally or pharmacologically identified.

\section{Rape by drug, not by man: degendering sexual assault}

These educational materials manage to reinscribe old-fashioned heterosexual norms while de-gendering sexual violence. The intention to commit the crime is displaced from the man to the drug: the criminal and sexist intent is not in the man, but instead the pill. A victim who testified before the US Congress hearings on the date rape drug bill of 1996 stated that "the drug [not the criminal] destroyed my life," adding "it's the perfect crime in a pill." 8

The relocation of misogyny and violent desires to the pill effects a recuperation of feminist activism around sexual assault that acknowledges the prevalence of rape but diverts attention away from gender: it is the pill, after all, that is predatory, not men. This displacement has the effect of pleasing feminists and law-and-order constituencies simultaneously. This is a task that the Clinton re-election campaign, within which the 1996 Act was passed, was keen to achieve, since it was necessary to consolidate the feminist support that has traditionally gone to the Democrats, while reassuring middle America that Clinton was not soft on crime. While official acts such as the 1996 federal US date rape drug act could be electorally "sold" to women voters as overdue recognition of the longstanding feminist argument that it is not the "dark stranger" but rather the "date" or the husband that is most likely to pose a risk to young women, the educational materials provided by official government sources all reproduce Victorian-melodramatic images of pretty maidens and lecherous men, rather than disseminating feminist images (of men as well as of women). It is significant that men are never encouraged to watch what their male friends do when out for the evening: the maidens are wholly "responsibilized" for their own risks. Information disseminated by sexual assault centres does mention the broader issues of gender power, and, tellingly, it tends to eschew posed photographs in favour of text. However, we have thus far found no explicit feminist critique of the US government's discourse on date rape drugs. 


\section{Safety in numbers: (heterosexual) female risk management}

The risk management techniques presented to female students in the lowtech, folksy format of handy "tips" are unusual in the neoliberal context of risk information and "informed choice" in that they rely on and construct a collectivity. Since date rape drugs are regarded as impairing and even abolishing the liberal subject's ability to calculate, individual responsibility and risk management is in this case of limited utility. Instead, a collective of "trusted friends" (who are rarely explicitly feminized, but whose gender is necessarily, structurally feminine) needs to be mobilized. Such mobilization of female networks is a plausible strategy because it can draw on existing relations of teenage and undergraduate female friendship. However, the gendered nature of these existing friendship networks, this gender-specific social capital, is rarely, if ever, explicitly acknowledged, as if for fear of appearing to sound feminist. The University of Alberta Web site encourages partiers to "stay in large groups of people," a piece of advice which, given the surrounding description of male lechery, seems to presuppose that the "people" who provide safety are female. The University of Toronto's campus police Rohypnol pamphlet similarly ends with a section entitled: "Protect yourself and your friends," a statement which implicitly addresses a female reader.

The "trusted friends" trope was not invented in the context of date rape drugs: alcohol education seminars for undergraduates often advise women to make pacts with each other before they go out to the effect that they will not leave the bar with anyone except the friends with whom they arrived. This advice underlines the persistence of old-fashioned gender dangers, since one can hardly imagine male undergraduates being interpellated in this way. But there are reasons why the date rape drug/club drug chronotope is a fertile ground for the sort of female network envisaged by the educational projects examined here, reasons rooted in the nature of the (perceived) risks of these particular substances and behaviours.

The tales about Rohypnol and GHB told in the literature emphasize the grave risks of losing both one's ability to plan and calculate and one's ability to remember events. Nowhere is there an explanation of why exactly it is so much worse to be raped and not remember it, than to be raped while fully conscious: it is simply assumed, in all the sources examined, that this is indeed the case. This is not new: one finds this assumption in the trite Victorian plot device of having a villain slip opium into someone's drink 
(as seen for example in Wilkie Collins's The Moonstone), as well as in the anxieties generated by, as Ian Hacking has argued, "multiple personality disorder." There are, no doubt, psychoanalytic explanations of the great fear that seems to attach to doing something, or having something done to one, without remembering afterwards or without willing it. But, to pursue a more historical line of inquiry, there is little doubt that fears of memory and consciousness loss called up by date rape drugs - whatever they might have meant in earlier panics about opiates, about "knock out drops" or "Mickey Finns" - have a particular significance in our own day because they represent the worst possible risk: the risk of losing the calculating subjectivity that is necessary for governing oneself in a neoliberal paradigm and monitoring one's own risks.

The collective risk-monitoring strategies suggested for addressing this problem of loss of individual capacity to reason and calculate, while highly dependent on hegemonic gender relations, are presented in ungendered language:

"When going to a bar, party, or social event, never go alone. Be with a friend whom you trust."

"Watch for unusual behaviour in your friends. If you suspect they are not acting like themselves, INTERVENE! Protect your friends from harm. The risks of having your friends angry with you are minimal compared to the harm they may be facing."

"Never accept a drink from anyone except the bartender or a trusted friend. If someone you don't trust offers to buy you a drink, have someone you do trust accompany them."

"Never leave your drink unattended."

"Never leave a bar or club with someone you have just met, especially if you are feeling intoxicated." ${ }^{\prime 9}$

That the trusted friends are always and necessarily female seems to go without saying. That these trusted friends are heterosexual as well as female is also assumed. The chronotope of the drug-haunted club or party, while postmodern and cool in most respects, is downright premodern in that women are never suspected of wanting to seduce other women; moreover, men are universally represented as posing a sexual risk to women. Thus, compulsory heterosexuality is reinscribed even as the stories and pictures tell tales which, one would think, would make young women 
eschew all heterosexual contact, for no man is truly and wholly safe. Similarly, the case of the trusted friends technologies for collective risk management, while drawing on feminist techniques for "taking back the night" and protecting one another so as to be able to circulate through public space without the aid of a male knight, nevertheless suppresses the feminist source of this type of technology for collectively managing risks. Moreover, it supresses the feminist telos that characterizes feminist education on sexual dangers. While the object of the old feminist techniques of watching out for one's sisters was to constitute something like "a women's community," in which women would be free to choose heterosexuality precisely because they no longer needed men to escort them or to provide for them, it is interesting that the pamphlets in question never utter the word "community" despite the obvious similarities between the tips provided to women partiers and those given to home-owners in communitypolicing literature. Young women are supposed to be "trusted friends," but only for the purposes of partying. The women's safety network is thus presented as specific to the chronotope of partying which is not surprising since the risks of drugs and sexual assault are also presented as contained within the club/rave/frat party chronotope. Thus, both the risks, and the measures to monitor and minimize those risks, reinscribe conventional heterosexuality even while acknowledging - through tales about nice guys slipping pills into girls' drinks - that perhaps it is the chronotope of conventional heterosexuality, not that of the club, that is truly risky.

\section{Conclusion: feminist fears, fears of feminism}

The current campaigns around youth party drugs, especially date rape drugs, allow for the governance both of rape and fear of rape. They take up the feminist critique of the police myth of rape - the dark stranger in the alley - by portraying the potential or actual assailant as white, welldressed, etc. At the same time, however, they disallow feminist analyses, favouring instead the Victorian melodrama so ably analyzed by Judy Walkowitz. The old narrative forms, however, do different kinds of work now. Our present moment has witnessed the growth of a sophisticated mix of knowledge formats that, while not confined to the Internet, seem to circulate with greatest ease in cyberspace, something which allows for the simultaneous gendering and degendering of the sexual risks that overdetermine these educational projects. 


\section{Notes}

We acknowledge the advice and support given by our colleagues in and around the Centre of Criminology, University of Toronto, especially Kelly Hannah-Moffatt, Joe Hermer, Rosemary Gartner, Ron Levi, Paddy Stamp, and Maximo Sozzo, and by the Toronto History of the Present Network. Special thanks to Pat O'Malley.

${ }^{1}$ See Eisner; Jenkins; Reynolds.

2 The emergence of Rohypnol as a social problem can be dated to a spate of newspaper stories, many in campus papers, about the dangers of the Rohypnol pills being brought back to the US by university students vacationing in Mexico over the March break of 1996.

3 At Canada's largest university, the University of Toronto, safety officers and campus police conducted "date rape drug" workshops for students who lived in residence from 1996 to 1999 . When asked why this was not being repeated in the 1999/2000 school year, one of the safety educators told us that there had been no reported cases of "date rape drug" use on campus. The educational efforts continue, however: posters about Rohypnol are prominently displayed in many female public bathrooms on campus.

4 See Walkowitz; Valverde.

5 See O'Malley.

${ }^{6}$ We owe the phrase "knowledge formats" to Ericson and Haggerty.

${ }^{7}$ A presentation on this topic by both authors in an undergraduate criminology class elicited tales about women students, always at some other university, who were victims of date rape drugs. At the same time, interviews with five well-placed safety, health, and student-service personnel at our own (very large) university failed to uncover a single documented case of "date rape drug" use.

${ }^{8}$ Lisa Celestin, quoted in "Legislation targets drug used in date rapes," LA Times (17 July 1996): 14.

9 Pamphlet entitled "Rohypnol," produced by the University of Toronto campus police. The McMaster University web site contains many of the same tips: "never go to a bar alone but with a [female] friend you trust"; "never leave your drink unattended"; "be suspicious of people who handle your drink or insist you accept a drink from them," and, somewhat contradictorily, "if YOU feel intoxicated with your first drink, ask for help." 


\section{Works Cited}

Bakhtin, M. "Forms of time and of the chronotope in the novel." The Dialogic Imagination. Austin: U of Texas P, 1981.

Derrida, J. Spectres of Marx. New York: Routledge, 1994.

Eisner, B. Ecstasy: The MDMA Story. Berkeley: Cronin, 1994.

Hacking, I. Rewriting the Soul: Multiple Personality and the Sciences of Memory. Princeton: Princeton UP, 1995.

Jenkins, P. Synthetic Panics: The Symbolic Politics of Designer Drugs. New York: New York UP, 1999.

Moore, D. "Risking Saturday Night: Regulating Student Alcohol Use Through 'Commonsense."' Theoretical Criminology (forthcoming).

O'Malley, P. "Risk and Responsibility." Foucault and Political Reason. Eds.

A. Barry, T. Osborne, and N. Rose. London: UCL P, 1996.

-. "Consuming Risks: Harm Minimization and the Government of Drug 'Users.'” Governable Places: Readings on Governmentality and Crime Control. Ed. R. Smandych. Dartmouth: Ashgate, 1999.

Simon, J. "Governing through Crime." The Crime Conundrum: Essays on Criminal Justice. Eds. L. Friedman and G. Fisher. Westview P, 1997.

Stanko, B. "Safety Talk: Conceptualizing Women's Risk Assessment as a "Technology of the Soul.'" Theoretical Criminology 1.4 (1997): 479-99.

Valverde, M. The Age of Light, Soap and Water: Moral Reform in English Canada 1880s-1920s. Toronto: McClelland and Stewart/Oxford, 1991.

Walkowitz, J. City of Dreadful Delight: Narratives of Sexual Danger in Late Victorian London. Chicago: U of Chicago P, 1992. 